\title{
Relationship between guideline treatment and health-related quality of life in asthma
}

\author{
L.G. Pont*, T. van der Molen", P. Denig*, G.T. van der Werf*, F.M. Haaijer-Ruskamp*
}

Relationship between guideline treatment and health-related quality of life in asthma. L.G. Pont, T. van der Molen, P. Denig, G.T. van der Werf, F. M. Haaijer-Ruskamp. (C) ERS Journals Ltd 2004.

ABSTRACT: The aim of this study was to compare the health-related quality of life (HRQL) of asthma patients treated according to the 1997 National Institute of Health (NIH) international asthma guideline and that of asthmatics receiving non-guideline treatment.

The suitability of 146 asthmatics' medication regimes was determined according to the 1997 NIH asthma guideline. Quality of life was assessed on a seven-point scale using the Asthma Quality of Life questionnaire.

Just over half of the patients were not currently using the treatment considered necessary for controlling their asthma. Patients treated according to the guideline $(n=72)$ had a significantly higher overall HRQL than patients with non-guideline treatment (5.7 versus 5.3). The differences were also significant for the subscales measuring symptoms and environmental exposure, but not for activities or emotional function.

An association between non-guideline treatment and a poorer health-related quality of life in asthma patients treated in general practice was observed. This study supports the role of evidence-based guidelines in daily practice. Further studies are needed to determine if guideline treatment is responsible for the increase in health-related quality of life observed in this work.

Eur Respir J 2004; 23: 718-722.
*Dept of Clinical Pharmacology, Groningen University Institute of Drug Exploration, and \#Dept of General Practice, University of Groningen, the Netherlands.

Correspondence: F.M. Haaijer-Ruskamp, Dept of Clinical Pharmacology, University of Groningen, Ant. Deusinglaan 1, 9713 AV Groningen, the Netherlands.

Fax: 31503632812

E-mail: f.m.haaijer-ruskamp@med.rug.nl

Keywords: Asthma

drug treatment

guidelines

primary care

quality of life

Received: July 182002

Accepted after revision: December 152003

This work was funded by an unconditional scholarship from the Groningen University Institute of Drug Exploration (GUIDE) awarded to L.G. Pont.
Asthma is a chronic inflammatory airway condition affecting $>8 \%$ of adults in Western Europe [1]. Like most chronic conditions, the majority of asthma patients are managed in general practice [2]. International consensus regarding optimal treatment for asthma has existed since the early 1990s, as evident in the international guidelines first published in 1992 [3]. These guidelines aimed to help healthcare professionals bridge the gap between current knowledge and daily practice, and to standardise and improve the quality of asthma care provided. Over the past decade these guidelines have been reviewed and updated [4], and at the time of the current study in 1999/2000 the most recent international guideline was that published in 1997 by the National Institute of Health (NIH) [5]. Pharmacotherapy is an important element in the optimal management of asthma as recommended in the guidelines. Common to all versions of the guidelines, the goals of asthma therapy are to improve the patient's quality of life by preventing chronic and troublesome symptoms, maintaining "normal" lung function, maintaining normal activity levels, preventing recurrent exacerbations and providing optimal pharmacotherapy with minimal adverse effects.

While the goals of asthma therapy focus on the patient, assessment of the guidelines and their effectiveness has focused on physicians. Little attention has been given to the effect of guidelines on patient outcomes, such as mortality, morbidity or quality of life in asthma. Prescriber adherence to the asthma guidelines with respect to diagnostic procedures, drug therapy and patient self-management counselling has been investigated [2, 6-8]. While explicit guidelines have been shown to improve physician clinical practice, it is not known if such improvement has similar positive effects on patient outcomes $[9,10]$. Earlier work on the effect of guidelines on patient outcomes concluded that there was little evidence that clinical guidelines are effective in improving patient outcomes, although the poor quality of the guidelines investigated was believed to have had a major influence on this finding [11]. More recent work has indicated that asthma patients receiving guideline-recommended drug therapies have less hospital admissions [12,13] and better lung function [14] than patients not treated according to the guidelines. What remains unknown is the effect of guidelines on the patient's asthmarelated quality of life. In this study, health-related quality of life (HRQL) in asthma patients managed in general practice who are treated according to the NIH asthma guideline were compared with the HRQL in those not receiving guideline recommended treatment.

\section{Materials and methods}

\section{Study subjects}

The Registratie Netwerk Groningen (RNG) is a general practice database from the northern Netherlands. At the time of the study, the RNG included 30,486 patients registered with 16 general practitioners (GP)s. All participating GPs use the database in place of paper medical records.

All patients were aged $18-49$ yrs with an anti-asthma medication (Anatomical Therapeutic Chemical classification group R03 [15]) or an asthma contact (International Classification 
of primary Care code R96 [16]) during 1997. Data from 1997 was used for recruitment to ensure that patients had chronic asthma. Patients no longer registered with an RNG doctor or receiving anti-asthma medications for nonasthma indications were ineligible. GPs invited eligible patients to attend a clinical appointment with a research assistant. A reminder letter was sent to nonrespondents within 3 months of the initial invitation. Anonymous age and sex, and prescribing data for nonresponding patients was obtained from the database to enable comparison between nonresponders and patients participating in the study. The local medical ethics committee approved the study and informed consent was obtained from each participant.

\section{Methods}

Participating patients attended a single research appointment (May-December 2000) where forced expiratory volume in one second (FEV1) was measured and a questionnaire regarding recent asthma symptoms, medication use and asthma-related quality of life was completed by each participant. FEV1 was assessed by an experienced research assistant trained in spirometry according to the standards of the American Thoracic Society using a Microlab 3300 spirometer (Micro Medical Ltd, Rochester, UK). For each participant the best of three readings was used.

\section{Definition of guideline adherence}

Each patient's treatment regime, as obtained from the interviews, was classified as adherent or nonadherent using an algorithm based on the recommendations from the NIH
Expert Panel Report 2 Guidelines for the Diagnosis and Management of Asthma [5]. Adherence to the guideline was defined as any drug or drug combination recommended in this international asthma guideline for the relevant asthma severity (table 1). Since improving lung function and reducing symptoms are important treatment aims, drug combinations from higher asthma severity classifications were also considered adherent for patients with a lower severity classification.

Self-reported medication use by patient interview has been shown to be a reliable method of obtaining information regarding current medication use [17, 18]. Accuracy of selfreported medication use was further improved by having patients bring all their current asthma medications to the clinical appointment. The research assistant also questioned patients during the clinical appointment about their current asthma medications, using both brand and generic names.

Since there is no objective severity classification for treated asthma patients, the severity classification from the international NIH guideline for pharmacological management of asthma was used [5]. This classification uses a combination of symptoms and lung function to determine asthma severity rather than relying on a single component. In accordance with these NIH criteria (table 1), questions referring to the frequency of night-time symptoms (less than twice a month, more than twice a month, once a week, more than once a week) and day-time symptoms requiring bronchodilator use (0-3 days per week, 3-6 days per week, 1-2 times per day, $\geqslant 3$ times per day) were used in combination with the FEV1 as assessed at the research appointment to classify the patients. Patients were assigned to the most severe grade in which a feature occurs. For example, a patient with night-time symptoms less than twice a month, but symptoms once to twice a day, and a FEV1 of $70 \%$ was assigned in class 3 .

Table 1.-Severity classification and treatment recommendation for the 1997 National Institute of Health asthma guideline

\begin{tabular}{|c|c|c|}
\hline & Severity classification ${ }^{\#}$ & Medication recommendations \\
\hline Class 1 & $\begin{array}{l}\text { Symptoms: } \leqslant \text { twice a week } \\
\text { Asymptomatic and normal PEF between } \\
\text { exacerbations } \\
\text { Exacerbations brief } \\
\text { Night time symptoms: twice a month } \\
\text { Lung function: FEV1 or PEF } \geqslant 80 \% \text { pred }\end{array}$ & $\begin{array}{l}\text { Inhaled SABA when needed } \\
\text { Salbutamol } 100-400 \mu \mathrm{g} \text { or } \\
\text { Terbutaline } 250-500 \mu \mathrm{g} \text { or } \\
\text { Fenoterol } 200 \mu \mathrm{g}\end{array}$ \\
\hline Class 2 & $\begin{array}{l}\text { Symptoms: >twice a week but }<\text { once a day } \\
\text { Exacerbations may affect activity } \\
\text { Night time symptoms: }>\text { twice a month } \\
\text { Lung function: FEV1 or PEF } \geqslant 80 \% \text { pred }\end{array}$ & $\begin{array}{l}\text { Inhaled SABA and ICS } \\
\text { Beclomethasone/budesonide } 200-400 \mu \mathrm{g} \text { or } \\
\text { Fluticasone } 100-250 \mu \mathrm{g} \text { twice daily } \\
\text { Cromoglycate } 5-10 \mathrm{mg} \text { four times daily may replace } \\
\text { ICS }\end{array}$ \\
\hline Class 3 & $\begin{array}{l}\text { Symptoms: daily } \\
\text { Daily inhaled SABA use } \\
\text { Exacerbations affect activity } \\
\text { Exacerbations: } \geqslant \text { twice a week } \\
\text { Night time symptoms: }>\text { once a week } \\
\text { Lung function: FEV1 or PEF }>60 \% \text { and } \\
\quad<80 \% \text { pred }\end{array}$ & $\begin{array}{l}\text { Inhaled SABA and ICS } \\
\text { Beclomethasone/budesonide } 800 \mu \mathrm{g} \text { or } \\
\text { Fluticasone } 500 \mu \mathrm{g} \text { twice daily } \\
\text { or } \\
\text { Inhaled SABA and ICS and inhaled LABA } \\
\text { ICS: beclomethasone/budesonide } 400 \mu \mathrm{g} \text { or } \\
\text { Fluticasone } 250 \mu \mathrm{g} \text { twice daily } \\
\text { LABA: salmeterol } 50-100 \mu \mathrm{g} \text { or } \\
\text { Formoterol } 6-24 \mu \mathrm{g} \text { twice daily }\end{array}$ \\
\hline Class 4 & $\begin{array}{l}\text { Symptoms: continual } \\
\text { Limited physical activity } \\
\text { Frequent exacerbations } \\
\text { Night time symptoms: frequent } \\
\text { Lung function: FEV1 or PEF } \leqslant 60 \% \text { pred }\end{array}$ & $\begin{array}{l}\text { SABA and high-dose ICS and LABA and/or } \\
\text { ipratropium } \\
\text { ICS: beclomethasone/budesonide } 800 \mu \mathrm{g} \text { or } \\
\text { Fluticasone } 500 \mu \mathrm{g} \text { twice daily } \\
\text { LABA: salmeterol } 50-100 \mu \mathrm{g} \text { or } \\
\text { Formoterol } 6-24 \mu \mathrm{g} \text { twice daily } \\
\text { Ipratropium } 20-40 \mu \mathrm{g}\end{array}$ \\
\hline
\end{tabular}

PEF: peak expiratory flow; FEV1: forced expiratory volume in one second; \% pred: \% predicted; SABA: short-acting $\beta$-agonists; ICS: inhaled corticosteroids; LABA: long-acting $\beta$-agonists. ${ }^{\#}$ : the presence of one or more of the features of severity is sufficient to place a patient in that category; an individual should be assigned to the most severe grade in which any feature occurs. 


\section{Health-related quality of life assessment}

HRQL was assessed using the Adult Asthma Quality of Life Questionnaire (AQLQ) [19]. The AQLQ is a validated disease-specific quality of life questionnaire consisting of 32 items measuring four domains of asthma-related health: 12 items assess symptoms, five measure emotional function, four assess exposure to environmental stimuli and 11 determine activity limitations due to asthma. The AQLQ uses a sevenpoint scale where a higher score corresponds to a better HRQL. Each participant completed the self-administered, Dutch language version of this instrument during the research appointment.

\section{Sample size}

In earlier studies using the AQLQ, the mean score for asthma patients treated in general practice ranged 4.6-6.0 [20]. In order to detect a difference in HRQL of $0.5, \geqslant 63$ patients with adherent and 63 with nonadherent treatment regimes were required. Previous work clinically assessing asthma treatment found the proportion of patients with pharmacotherapy not adherent to that recommended in the guidelines to be $\sim 60 \%[2,7]$. Thus, the study aimed to recruit 160 patients in order to achieve a power of 0.80 with an alpha of 0.05 .

\section{Analysis}

An unpaired t-test was used to assess the difference in overall HRQL and in scores on the four subscales between asthmatics treated according to the guidelines and those with non-guideline treatment.

\section{Results}

\section{Study population}

In total, 369 eligible patients were invited to attend a clinical appointment, of which 152 patients were willing to participate. After initial contact by the researchers, six patients were unable to attend an interview during the study period, leaving a final study population of 146 (response rate $39.6 \%$ ). There was no significant difference with respect to sex (58.2 and $57.8 \%$ female, respectively) between participating patients $(\mathrm{n}=146)$ and nonrespondents $(\mathrm{n}=223)$. Participating patients were slightly older (aged 39.8 versus $35.8 \mathrm{yrs}$, $\mathrm{p}<0.05$ ). There were no significant differences between participating and nonresponding patients in the mean volume prescribed per patient for inhaled short-acting $\beta$-agonists, inhaled corticosteroids, inhaled anticholinergics and oral salbutamol.

\section{Medication use}

Patients' severity classification and current asthma medication use are shown in table 2. Six patients $(4.1 \%)$ reported using no current asthma medications. Of the 38 patients not using a short-acting $\beta$-agonist, six were using ipratropium, 11 a long-acting $\beta$-agonist, and two were using both. Salbutamol was the most commonly used short-acting $\beta$ agonist used by $88.2 \%(90 / 102)$ of patients reporting use of a short-acting $\beta$-agonist. Of the remaining short-acting $\beta$-agonist users 12 used terbutaline and one each rimiterol and fenoterol. One patient was using both salbutamol and terbutaline, and one patient salbutamol and rimiterol.

The most commonly used inhaled corticosteroid was budesonide (59/95, 62.1\%). Twenty-two patients used beclomethasone and 14 patients fluticasone. Long-acting $\beta$-agonists were used by 22 patients. Salmeterol was used by 13 patients and formoterol by nine patients. While $70 \%$ of patients were using an inhaled short-acting $\beta$-agonist and $65 \%$ of patients an inhaled corticosteroid, only $42 . \%(62 / 146)$ used an inhaled short-acting $\beta$-agonist and an inhaled corticosteroid.

\section{Non-guideline treatment regimes}

Just over half of the treatment regimes were considered as nonadherent to guideline recommendations (table 2). Of the 14 patients in severity class 1 not using a short-acting $\beta$-agonist, none were using ipratropium and two were using a long-acting $\beta$-agonist. The majority of these patients $(n=12)$ were using inhaled corticosteroids.

The main reason for nonadherent therapy among class 2 patients $(n=5)$ was the lack of anti-inflammatory treatment $(\mathrm{n}=4)$. One patient was using anti-inflammatory treatment and a long-acting $\beta$-agonist.

Lack of anti-inflammatory treatment was also a major factor contributing to nonadherent treatment for patients in asthma severity class 3 . Of the 40 patients with a treatment regime not recommended in the guideline, 27 were not currently using any anti-inflammatory medication and one was using cromoglycate in place of the inhaled corticosteroid recommended in the guideline. Eighteen class 3 patients were not using a short-acting $\beta$-agonist. From these 18, five were using ipratropium, four a long-acting $\beta$-agonist and one was using both. There were six patients in this severity class with neither a short-acting $\beta$-agonist nor an inhaled corticosteroid.

In severity class 4 , the most severe class, there were 13 patients without a guideline-recommended treatment regime. Of the ten patients with no short-acting $\beta$-agonist, one had ipratropium, five a long-acting $\beta$-agonist and one had both.

Table 2. - Patients' classification of severity and medication regimes

\begin{tabular}{|c|c|c|c|c|c|}
\hline & Class 1 & Class 2 & Class 3 & Class 4 & Total \\
\hline Total & 51 & 9 & 70 & 16 & 146 \\
\hline Adherent regimes & $35^{\#}(69)$ & $4(44)$ & $30(43)$ & $3(19)$ & 72 \\
\hline Nonadherent regimes & & & & & 74 \\
\hline No current medication & $2(4)$ & 0 & $4(6)$ & 0 & \\
\hline No short-acting $\beta$-agonist & $14(27)$ & $1(11)$ & $14(20)$ & $9(56)$ & \\
\hline Only short-acting $\beta$-agonist & & $4(44)$ & $19(27)$ & $2(13)$ & \\
\hline Other regimes lacking inhaled corticosteroid & & 0 & $3(4)$ & $1(6)$ & \\
\hline Other regimes lacking long-acting $\beta$-agonist & & & & $1(6)$ & \\
\hline
\end{tabular}

Data are presented as $\mathrm{n}(\%)$. ${ }^{*}$ : including nine with only a short acting $\beta$-agonist. 
Three patients had no anti-inflammatory medication and one was using cromoglycate in place of an inhaled corticosteroid. There were six patients without either a long-acting $\beta$-agonist or ipratropium.

\section{Health-related quality of life}

For the total patient population, the mean HRQL was $5.5 \pm 1.0$. The HRQL was observed to decrease as asthma severity increased from $6.1 \pm 0.7$ for patients in severity class 1 , $5.5 \pm 0.4$ for severity class $2,5.2 \pm 0.9$ for severity class 3 and $4.8 \pm 1.2$ for severity class 4 .

As seen in table 3, asthma patients treated according to the guideline had a significantly higher HRQL than those with non-guideline regimes (5.7 versus $5.3, \mathrm{p}<0.01)$. For all four subscales, there was a positive difference for patients treated according to the guideline, which was significant for the domains "symptoms" and "environmental exposure".

\section{Discussion}

A number of treatment patterns not in accordance to the recommendations in the NIH guideline were found. More than half of the patients participating in this study were not currently using the treatment considered necessary for controlling their asthma. Around a third of patients were not using any short-acting $\beta$-agonist. Disturbingly, this proportion was even higher in patients classified in severity class 4. A small number of such patients were using ipratropium, which although not recommended in the guideline as a bronchodilator, has traditionally been used in this role. A larger number of patients without a short-acting $\beta$-agonist were using a long-acting $\beta$-agonist. While the pharmacokinetics of formoterol may support its use as a bronchodilator, the majority of patients in this study were using salmeterol. Salmeterol does not share the same pharmacokinetic profile as formoterol and may not be suitable for rapid relief of symptoms in an acute situation. Under use of inhaled corticosteroids was also evident in the study population. Whether these patients had ever been prescribed a corticosteroid is not known and further investigation is needed to discover if this is a prescriber or patient problem. Similar patterns of poor use of preventive medication and lack of prescribed rescue medication have been identified in other studies, and were found to be associated with an increased risk of hospitalisation [12, 13].

The current study showed that asthma patients treated according to the NIH guideline also have a significantly better HRQL than patients not treated according to this guideline, especially in terms of symptoms and environmental exposure. It has been argued that clinical relevance of differences in quality of life is of more importance to the prescriber than statistical significance [21]. A difference of 0.5 points on the AQLQ has been determined to represent a clinically relevant difference for measuring change within a single patient allowing for individual variation [22]. However, AQLQ scores were compared between two patient groups where it can be expected that the individual variation within the two groups should be similar and a smaller difference could be considered clinically relevant. Thus the differences observed of 0.4 points in overall HRQL, as well as in the symptoms subscale, and of 0.6 points in the environmental exposure subscale are not only statistically significant but also borderline clinically relevant. Non-guideline treatment seems to have the least effect on emotional function of the asthma patients, which is in line with other studies in which the treatment regime appeared to have more impact on symptoms and environmental exposure than on emotional function [23].

In general, the HRQL among the patients participating in the study (mean 5.5) was relatively high. Other studies have also found that the average HRQL in mild-to-moderate asthma patients is close to that of the general population [24]. A strong link between asthma-related quality of life and disease severity has been reported [20, 25], and this relationship was also observed in the current study. For all patients, irrespective of their treatment, the HRQL decreased from 6.1 for severity class 1 patients to 4.8 for the most severe patients, which is similar to that seen in other studies [20]. It is most likely that the relationship between HRQL and asthma severity is due to the relationship between HRQL and asthma symptoms [26, 27].

Since no objective severity classification for treated asthma patients exists, the severity classification presented in the NIH guideline was used in the current study [5]. This classification uses a combination of day-time and night-time symptoms, need for inhaled short-acting $\beta$-agonist and lung function to determine asthma severity. It is often used to categorise patients in research, but may underestimate actual severity in patients that are well controlled with treatment [28]. In a first attempt to validate the assessment of asthma severity in patients mostly taking treatment, it was concluded that the severity classification recommended by clinical guidelines, such as the NIH, is useful for clinical assessment and management of asthma patients in general practice [29]. In the current study, a possible underestimation of severity does not affect the assessment on whether the treatment is adherent to the guideline, because treatment recommendations follow a step-wise progression. Treatment for a higher severity is always in addition to treatment from a lower severity either with respect to increasing the dose of an existing medication or the addition of a new medication. Thus, adequate treatment according to the guideline for a particular severity class implies that the treatment will also be considered adequate for a lower severity class.

While the response rate in this study was rather low (40\%), sufficient numbers of patients with adherent and with nonadherent treatment regimes were recruited. There were no large differences between participants and nonrespondents in terms of age, sex or prescribed medication. The low response rate may be related to the age group targeted (18-49 yrs), since this group comprises a large proportion of the workforce and

Table 3. - Health-related quality of life scores (HRQL) measured on seven-point scales

\begin{tabular}{|c|c|c|c|c|}
\hline & All asthma patients & Adherent medication regime & Nonadherent medication regime & p-value ${ }^{\#}$ \\
\hline Activities & $5.4 \pm 1.1$ & $5.5 \pm 1.0$ & $5.2 \pm 1.1$ & 0.079 \\
\hline Symptoms & $5.5 \pm 1.1$ & $5.7 \pm 1.0$ & $5.3 \pm 1.1$ & 0.047 \\
\hline Emotional function & $6.0 \pm 1.0$ & $6.1 \pm 0.9$ & $5.9 \pm 1.1$ & 0.347 \\
\hline Environmental exposure & $5.3 \pm 1.2$ & $5.6 \pm 1.0$ & $5.0 \pm 1.3$ & 0.002 \\
\hline Overall HRQL & $5.5 \pm 0.9$ & $5.7 \pm 0.8$ & $5.3 \pm 1.0$ & 0.008 \\
\hline
\end{tabular}

Data are presented as mean \pm SD. ${ }^{*}$ : testing for difference between adherent and nonadherent regimes. 
may be less willing to attend the research appointment.

To determine the patients' current asthma medication regime, each patient was questioned about their asthma medications using both brand and generic names, as well as having each patient bring their current medications along to the clinical appointment. The method focuses on what the patient is currently using, either daily or as needed, and not necessarily on what the doctor has prescribed. It has been reported that specific patient groups do not redeem as many as $27 \%$ of prescriptions [30], thus a doctor may have prescribed a guideline-based regime that a patient has chosen not to have dispensed. This indicates that from a GP's perspective this study may underestimate the proportion of patients being prescribed medication according to the guidelines.

In conclusion, a significant proportion of non-guideline treatment in asthma patients in general practice was observed, which was associated with a poorer health-related quality of life. Further studies are needed to determine if treatment adhering to that recommended in the guidelines is responsible for the better asthma-related quality of life observed in this work. For doctors and other healthcare professionals this study emphasises the relevance of using evidence-based treatment guidelines in daily medical practice.

\section{References}

1. Rabe KF, Vermeire PA, Soriano JB, Maier WC. Clinical management of asthma in 1999: the Asthma Insights and Reality in Europe (AIRE) study. Eur Respir J 2000; 16: 802-807.

2. Roghmann MC, Sexton M. Adherence to asthma guidelines in general practices. J Asthma 1999; 36: 381-387.

3. National Institute of Health. International Consensus Report on Diagnosis and Treatment of Asthma. Clin Exp Allergy 1992; 22: Suppl. 1, 1-72.

4. National Institute of Health. Global Strategy for Asthma Management and for Asthma Management and Prevention NHLBI/WHO Workshop. NIH publication number: 95-3659: NHLBI/WHO, 1995.

5. National Institute of Health. Expert Panel Report 2: Guidelines for the Diagnosis and Management of Asthma. NIH publication number: 97-4051: National Institute of Health, 1997.

6. Legorreta AP, Herman JC, $\mathrm{O}^{\prime}$ Connor RD, Hasan MM, Evans R, Leung KM. Compliance with national asthma management guidelines and specialty care: a health maintenance organization experience. Arch Intern Med 1998; 158: 457-464.

7. Taylor DM, Auble TE, Calhoun WJ, Mosesso VNJ. Current outpatient management of asthma shows poor compliance with International Consensus Guidelines. Chest 1999; 116: $1638-1645$.

8. Veninga CC, Lagerlov $\mathrm{P}$, Wahlstrom R, et al. Evaluating an educational intervention to improve the treatment of asthma in four European countries. Drug Education Project Group. Am J Respir Crit Care Med 1999; 160: 1254-1262.

9. Grimshaw JM, Russell IT. Effect of clinical guidelines on medical practice: a systematic review of rigorous evaluations. Lancet 1993; 342: 1317-1322.

10. Lagerlov P, Loeb M, Andrew M, Hjortdahl P. Improving doctors' prescribing behaviour through reflection on guidelines and prescription feedback: a randomised controlled study. Qual Health Care 2000; 9: 159-165.

11. Worrall G, Chaulk P, Freake D. The effects of clinical practice guidelines on patient outcomes in primary care: a systematic review. Can Med Assoc J 1997; 156: 1705-1712.
12. Nestor A, Calhoun AC, Dickson M, Kalik CA. Crosssectional analysis of the relationship between national guideline recommended asthma drug therapy and emergency/hospital use within a managed care population. Ann Allergy Asthma Immunol 1998; 81: 327-330.

13. Piecoro LT, Potoski M, Talbert JC, Doherty DE. Asthma prevalence, cost, and adherence with expert guidelines on the utilization of health care services and costs in a state Medicaid population. Health Serv Res 2001; 36: 357-371.

14. Jans MP, Schellevis FG, Le Coq EM, Bezemer PD, van Eijk JT. Health outcomes of asthma and COPD patients: the evaluation of a project to implement guidelines in general practice. Int $J$ Qual Health Care 2001; 13: 17-25.

15. World Health Organisation. WHO Collaborating Centre for Drug Statistics Methodology. ATC Index with DDDs. Oslo, World Health Organisation, 1999.

16. World Organisation of Family Doctors (WONCA). ICPC-2: International Classification of Primary Care 2nd edn. Oxford, Oxford Medical Publications, 2000.

17. Laumann JM, Bjornson DC. Treatment of Medicaid patients with asthma: comparison with treatment guidelines using disease-based drug utilization review methodology. Ann Pharmacother 1998; 32: 1290-1294.

18. West SL, Savitz DA, Koch G, Strom BL, Guess HA, Hartzema A. Recall accuracy for prescription medications: self-report compared with database information. $\mathrm{Am}$ $J$ Epidemiol 1995; 142: 1103-1112.

19. Juniper EF, Guyatt GH, Epstein RS, Ferrie PJ, Jaeschke R, Hiller TK. Evaluation of impairment of health related quality of life in asthma: development of a questionnaire for use in clinical trials. Thorax 1992; 47: 76-83.

20. Ehrs PO, Aberg H, Larsson K. Quality of life in primary care asthma. Respir Med 2001; 95: 22-30.

21. Juniper EF. Quality of life questionnaires: does statistically significant $=$ clinically important? J Allergy Clin Immunol 1998; 102: 16-17.

22. Juniper EF, Guyatt GH, Willan A, Griffith LE. Determining a minimal important change in a disease-specific Quality of Life Questionnaire. J Clin Epidemiol 1994; 47: 81-87.

23. Juniper EF, Svensson K, O'Byrne PM, et al. Asthma quality of life during 1 year of treatment with budesonide with or without formoterol. Eur Resp J 1999; 14: 1038-1043.

24. van der Molen T, Sears MR, de Graaff CS, Postma DS, Meyboom-de Jong B. Quality of life during formoterol treatment: comparison between asthma-specific and generic questionnaires. Canadian and the Dutch Formoterol Investigators. Eur Respir J 1998; 12: 30-34.

25. Moy ML, Israel E, Weiss ST, Juniper EF, Dube L, Drazen JM. Clinical predictors of health-related quality of life depend on asthma severity. Am J Respir Crit Care Med 2001; 163: 924-929.

26. Vollmer WM, Markson LE, O'Connor E, et al. Association of asthma control with health care utilization and quality of life. Am J Respir Crit Care Med 1999; 160: 1647-1652.

27. Osman LM, Calder C, Robertson R, Friend JA, Legge JS, Douglas JG. Symptoms, quality of life, and health service contact among young adults with mild asthma. Am J Respir Crit Care Med 2000; 161: 498-503.

28. Cockcroft DW, Swystun VA. Asthma control versus asthma severity. J Allergy Clin Immunol 1996; 98: 1016-1018.

29. Ng TP. Validity of symptom and clinical measures of asthma severity for primary outpatient assessment of adult asthma. Br J Gen Practice 2000; 50: 7-12.

30. Beardon PH, McGilchrist MM, McKendrick AD, McDevitt DG, MacDonald TM. Primary non-compliance with prescribed medication in primary care. BMJ 1993; 307: 846-848. 